\title{
There is no haecceitic Euthyphro problem
}

\author{
Alexander Skiles \\ The University of Gothenburg
}

Consider the view that each individual possesses a haecceity: a non-qualitative property the instantiation of which is both necessary and sufficient to be that very individual. ${ }^{1}$ One reason to believe in the existence of haecceities - perhaps the reason, and certainly the most influential - is that they are required to explain why any one individual is numerically distinct from another even when the two are qualitatively exactly alike, as it is with the pair of iron spheres famously discussed by Max Black (1952). According to this line of reasoning, what explains why Black's iron spheres are two in number cannot merely be a difference in their qualitative properties. Rather, it is the fact that they possess two different haecceities, the numerical distinctness of which is taken as brute.

Jason Bowers and Meg Wallace (2018) have argued that a Euthyphro-style dilemma arises for those who base their belief in haecceities on Black-style considerations. Consider a case of fission in which one individual divides into many, such as the familiar one of an amoeba splitting in two across a period of time. (Bowers and Wallace discuss an analogous dilemma involving cases of fusion, where two individuals combine into one; nothing will turn on differences between the two

\footnotetext{
${ }^{1}$ I should stress that the view in question neither entails nor is entailed by haecceitism, the modal thesis that reality could have differed in non-qualitative respects without differing in any qualitative respects. It also takes no stance on what type of property a haecceity is, or whether an individual instantiates one or many. See Bowers and Wallace (2018: fn. 1) and Cowling (2016: §2) for further overview. All undated parenthetical citations are to Bowers and Wallace's article.
} 
dilemmas, so I set this one aside.) Supposing that there are haecceities, then accompanying this material change is a further change in how many of them are instantiated: at first there was one, and then there are two. If so, then according to Bowers and Wallace, a Euthyphronic question arises regarding which change explains which: 'did the amoeba split in two because two haecceities came to be instantiated, or did two haecceities come to be instantiated because the amoeba split in two?' (17).

In taking the first horn, Bowers and Wallace argue that it would be ill-advised to say that "perfectly ordinary physical events are due to obscure changes in purely abstract entities' (15), for the only accounts on offer are underdeveloped at best, and absurd at worst. It is not as though the amoeba's splitting in two results from the amoeba's haecceity splitting in two. Other accounts of 'haecceitic activity', such as those due to Plato and Proclus, are similarly dubious (18-20).

In taking the second horn - to say that because of the amoeba's splitting, two haecceities came to be instantiated when there was once just one - Bowers and Wallace argue that this conflicts with the Black-style argument for haecceities canvassed earlier. The raison d'etre for haecceities is, supposedly, to explain numerical diversity among individuals. If so, then according to Bowers and Wallace, a problematic explanatory circularity emerges:

The very idea of splitting presupposes numeric diversity. Maude could not have split unless doing so resulted in additional individuals. To even say 'Maude is splitting' presupposes this resultant diversity. If we ask what makes it true that Maude is splitting, as opposed to doing something else, like dancing or thinking, part of the answer must cite the fact that more than one individual is involved. Maude's splitting, in other words, is made possible by the phenomenon of numeric diversity. (17, emphasis in original) 
According to Bowers and Wallace, the amoeba's splitting is at least partly explained by the fact that the splitting process began with only one individual, and culminated in the appearance of two. This is a fact about a change in how many individuals there are, and thus one that the believer in haecceities explains in terms of a change in how many of these are instantiated. But the entire point behind grasping the second horn was to say that the amoeba's splitting explains this change in how many haecceities are instantiated, not the other way around. Those who grasp the second horn must therefore abandon the classic argument for haecceities '[o]n pain of circularity' (17).

Bowers and Wallace have dubbed this dilemma 'the Haecceitic Euthyphro' (15). Yet in fact, the dilemma has little to do with haecceities specifically. More or less the same reasoning appears to threaten the viability of Platonistic explanations of numerical diversity among individuals more generally. Consider the view that it is the possession of certain causally inert, spatially unlocated qualitative properties - not haecceities - that explain numerical diversity among individuals. Then did the amoeba split in two because two such qualitative properties came to be instantiated, or did two of these come to be instantiated because the amoeba split in two? The view in question faces the same awkward choice between explanatory obscurity in grasping the first horn, or explanatory circularity in grasping the second horn. That the view in question traffics in causally inert, spatially unlocated qualitative properties instead of haecceities appears to make little, if any, difference to the dilemma's force. As a case in point, Bowers and Wallace seem to imply that grasping the first horn of the Haecceitic Euthyphro would be especially 'mysterious', as haecceities 'contribute nothing to the qualitative character of their possessors, so their presence cannot be seen, smelt, or directly detected in any way' (15). But if there is something mysterious here, appealing to causally inert and spatially unlocated qualitative properties does little to remove it. It is mysterious how 
Platonistic entities of any type could be empirically detectable - even qualitative ones - as even those sympathetic to Platonism concede (cf. Swoyer 2008: 27).

Likewise, my diagnosis of where Bowers and Wallace's dilemma goes wrong applies equally well to haecceitic and qualitative versions of it, although to keep matters concise I will focus on the former (how to extend it to the latter will be obvious). Let us grant to Bowers and Wallace that it would be problematic to posit obscure activity among haecceities, or to jettison the traditional reason for believing that there are haecceities in the first place. Moreover, let us grant the implicit 'chaining' assumption in the second horn of Bowers and Wallace's dilemma: if a fact, $p$, is at least partially explained by a fact of numerical diversity, $q$, which in turn is at least partially explained by a fact about haecceities, $r$, then $p$ is also at least partially explained by $r$. (Another type of response to Bowers and Wallace's dilemma - one I will not explore here - is to reject this instance of the chaining of metaphysical explanations: cf. Schaffer 2012 and Litland 2013 for discussion). Even granting all of this, the reasoning underlying the Haecceitic Euthyphro - specifically, the argument against taking the second horn - is fallacious, for it rests on an equivocation.

Specifically, Bowers and Wallace say little about how 'because', 'in virtue of', 'due to', 'results from', and other explanatory language used to set up the dilemma is to be understood, beyond that it concerns an atemporal form of dependence 'easily grasped by professional philosophers and undergraduates alike' (15). Yet there are at least $t$ wo types of atemporal explanatory dependence of relevance to metaphysics, and the Haecceitic Euthyphro arises only by failing to distinguish them. In taking the second horn, believers in haecceities explain why there is was a change in the number of haecceities instantiated in terms of the amoeba's splitting. Doing so, however, is entirely 
compatible with one then explaining what it is for the amoeba to split in terms of a change in the number of haecceities instantiated. Since no problematic circularity results when these two types of explanatory dependence run in opposite directions - indeed, examples of this 'circularity' are utterly familiar - it follows that there is no haecceitic Euthyphro problem.

The distinction between metaphysically explaining why a fact holds vs. what it is for it to hold is often subsumed under the distinction between stating what grounds a fact vs. what lies in the fact's essence (cf. Fine 2012; 2015). Although I will follow suit, what matters for present purposes is that there is such a distinction, regardless of whether one characterizes it in this particular fashion. ${ }^{2}$ What I have in mind is simply the difference between specifying what a fact itself at least partially 'consists in' and 'constitutively involves' (and thus what is 'part of its very nature'), as opposed to instead specifying the 'deeper' facts that non-causally 'give rise' to it on a particular occasion. Put in this rough and intuitive but recognizable) manner, it is a commonplace that these two ways to account for a fact can come apart. Specifying why a particular creature is in a state of consciousness in terms of neurophysiological features of its brain clearly leaves it open what it is for this creature to be in this state (is it, for instance, to be in a certain functional state?). And even if functionalists correctly specify what it is for this creature to be conscious, why it is conscious on

\footnotetext{
${ }^{2}$ For instance, one might follow Audi (2015), who draws basically the same distinction I do, calling it the distinction between explanation and explication. Although Audi denies that explications are explanations, that disagreement between my view and his need not detain us here. For even Audi grants that 'in virtue of', 'makes it the case that', and other language used to express explanations are often used by philosophers to express explications (2015: 209). Thus, those with Audi's view can rephrase all that I go on to say in terms of two different uses of explanatory language in metaphysics (as opposed to two different types of metaphysical explanation) without affecting anything of substance.
} 
this particular occasion may well remain wholly opaque absent further (presumably empirical) investigation. The point here applies not only to matters of mind, of course: philosophers across the discipline are often quick to emphasize whether they aim to propose the one type of metaphysical explanation, or the other (cf. Audi 2015, Greenberg 2014, Skiles 2015, and Sober 1984: 75).

Not only do the two types of metaphysical explanation come apart. Moreover, there are cases in which the two run in opposite directions. Far from being an exotic phenomenon, instances of the determinable-determinate relation - which are widely treated as textbook cases of metaphysical explanation - fit precisely this pattern. In one direction: an individual's being red, spherical, and six kilograms in mass at least partially ground its having colour, shape, and mass (respectively), and thus having these determinate properties at least partially explains why it has these determinable properties (cf. Rosen 2010: 126 and Schaffer 2012: 127). Yet in the other direction: it is part of the essential nature of an individual's being red, spherical, and six kilograms in mass that it has colour, shape, and mass (respectively), and thus having these determinable properties at least partially explains what it is for it to have these determinate properties (cf. Correia 2006: 756 and Dasgupta 2016: 386). ${ }^{3}$ Similar cases in which these two types of metaphysical explanation run in opposite directions involve more contentious matters. For instance, although it is part of what it is for multiple things to share a property that they resemble in a respect - indeed, Paul Audi (2013: 754) calls this a "truism" - realists about universals will nonetheless disagree with resemblance

\footnotetext{
3. Note that in saying that at least part of what it is for an individual to be red (for example) is for it to be coloured, I do not imply that its being red just is its being coloured, nor even that there is some further condition, $C$, such that its being red just is its being both coloured and $C$ (cf. Dasgupta 2016: 386)
} 
nominalists over whether facts about property-sharing 'give rise' to resemblances, or vice versa (cf. Audi 2015: 210).

Return now to the haecceitic Euthyphro problem. Bowers and Wallace, recall, have argued that their best take on cases of fission ensnares believers in haecceities in an explanatory circle. Yet the 'circularity' involved here is, I claim, nothing more than the seemingly innocuous 'circularity' displayed in the cases above.

On the one hand, Adams (1979), Rosenkrantz (1993), and originally Duns Scotus - whom Bowers and Wallace single out as offering haecceity-based explanations of numerical diversity (19) - more or less explicitly treat haecceities as playing a role in explaining what it is for individuals to be distinct. Thus Rosenkrantz, in a chapter titled 'Metaphysical Explanations', describes himself as providing an 'analysis' of individuation by appeal to haecceities, where 'to analyse a concept, $C$, is to explicate $C$, that is, to enhance one's understanding of $C$ by explaining what it is for something to be an instance of $C^{\prime}$ (1993: 73, emphasis in original). Similarly, Adams repeatedly characterizes himself as concerned with what the 'thisness' of an individual 'consists in', and whether each is 'analysable into, equivalent with, or even identical to, purely qualitative properties or suchnessess, as claimed by Leibniz' (1979: 10, 20). And for his part, Duns Scotus uses the term 'haecceity' to refer to an individual's individuality, not to the factor responsible for an individual's individuality, which he instead refers to as its 'singular essence' and repeatedly ties it to Aristotle's notion of essence, which concerns what it is to be a given individual (cf. King 2005). These believers in haecceities only explicitly commit to saying that a change in how many haecceities are instantiated 
helps explain what it is for the amoeba to split, and it is only in this sense that believers in haecceities more generally must commit to the second fact being 'presupposed' and 'made possible' by the first (as Bowers and Wallace put it before: 17).

On the other hand, I see no good reason why believers in haecceities must commit to anything other than the claim that the amoeba's splitting explains why additional haecceities came to be instantiated. Indeed, given an analogy that Bowers and Wallace use to illustrate the type of metaphysical explanation at issue here, this claim is all that believers in haecceities should commit to. According to Bowers and Wallace, if the amoeba's splitting explains the change in how many haecceities are instantiated, then this makes the relevant haecceitic change 'easier to accept' in the same way that treating 'immaterial mental states ... as epiphenomena, or as dependent by-products of physical changes' makes immaterial mental states easier to accept (15, emphasis in original). But I know of no epiphenomenalist who claims that part of what it is to be in an immaterial mental state involves the neurophysiological states it happens to be a by-product of. Rather, what epiphenomenalists claim is that states of the latter type explain why a creature happens to be in states of the former type on a particular occasion. Similarly, believers in haecceities need only maintain that the amoeba's splitting explains why additional haecceities came to be instantiated. ${ }^{4}$

Figuring out the exact features of metaphysical explanations of the why vs. what is it variety and how the two are related is, of course, well beyond what I can hope to accomplish here. For instance,

\footnotetext{
${ }^{4}$ That said, arguably no problematic circularity results even if these two facts what is it-explain each other: cf. Barnes (2018), who argues for the possibility of symmetric ontological dependence by pointing to the plausibility of certain symmetric essentialist 'what is it' statements.
} 
one complication relevant to the present discussion comes from Fine (2015: 306-307). Fine claims that if grounding and essential connectedness are both 'determinative' or 'constitutive' relations, then $X$ 'will not in general (and perhaps will never be)' a ground of $Y$ when $Y$ is part of $X$ 's essence. In reply, Fabrice Correia and I (2017) develop an account of grounding and essence that entails Fine's claim, yet we construe this entailment as a problem, due to how intuitive it is to think that having a determinable property is both essential to and grounded in having the relevant one of its determinates. Fortunately, one of the strategies Correia and I offer for dealing with this problem can be employed here: namely, to construe the what is it-explanation in determinable-determinate cases as concerning not what it is for it to be the case that $a$ is $F$ (what we call a claim of alethic essence), but rather as concerning what it is to be $F$ (what we call a claim of generic essence). Similarly, the believer of haecceities can be read as explaining not what it is for the amoeba to be splitting, but rather as explaining what it is to be splitting. Seen in this light, the explanans of the haecceity believer's what is it-explanation is not even the same as the explanandum of their whyexplanation, and thus Bowers and Wallace's circularity charge is undermined from the start. Of course, though, whether this complication must be bothered with in the first place hinges on a more extensive discussion of Correia and my dispute with Fine than I can engage in here.

Rather, my goal in this article has been more modest. I have attempted to show that cases where the two varieties of metaphysical explanation at least appear to run in opposite directions are normal and unobjectionable (or at least can be construed in such a way, apropos the above). I then attempted to show that the metaphysical explanations that believers in haecceities would presumably offer in cases of fission are just a specific instance of this apparently normal and unobjectionable more general phenomenon. Since belief in haecceities involves no explanatory circularity - 
or at any rate, certainly not one that is 'repugnant to the intellect' (21), as Bowers and Wallace charge - I conclude that there is no haecceitic Euthyphro problem. ${ }^{5}$

\section{Funding}

This work was supported by the Riksbanken Jubileumsfond and the Swiss National Science Foundation.

\section{References}

Adams, R. M. 1979. Primitive thisness and primitive identity. Journal of Philosophy 76: 5-26.

Audi, P. 2013. How to rule out disjunctive properties. Nô̂s 47: 748-66.

Audi, P. 2015. Explanation and explication. In The Palgrave Handbook of Philosophical Methods, ed. C. Daly, 208-30. London: Palgrave Macmillan.

Barnes, E. 2018. Symmetric dependence. In Reality and its Structure, ed. R. Bliss and G. Priest, 50-69. Oxford: Oxford University Press.

\footnotetext{
${ }^{5}$ Many thanks to Ricki Bliss, Jason Bowers, Andrew Brenner, Darragh Byrne, Fabrice Correia, the Columbia University ‘Metaphysics and Beer’ Group (especially Richard Booth, Martina Botti, Yifan Li, Billy McCarthy, Devin Morse, Andrew Richmond, and Achille Varzi), Dan Korman, David Kovacs, David Liggins, Anna-Sofia Maurin, Maria Scarpati, Robin Stenwall, Naomi Thompson, and two anonymous Analysis referees for their comments and encouragement.
} 
Black, M. 1952. The identity of indiscernibles. Mind 61: 153-64.

Bowers, J. and M. Wallace. 2018. The haecceitic Euthyphro problem. Analysis 78: 13-22.

Correia, F. 2006. Generic essence, objectual essence, and modality. Nô̂s 40: 753-67.

Correia, F. and A. Skiles. 2017. Grounding, essence, and identity. Philosophy and Phenomenological Research. DOI: 10.1111/phpr

Cowling, S. 2016. Haecceitism. In The Stanford Encyclopedia of Philosophy (Fall 2016 edition), ed. E. Zalta. URL $=<$ https://plato.stanford.edu/archives/fall2016/entries/haecceitism/ $>$

Dasgupta, S. 2016. Metaphysical rationalism. Noûs 50: 379-418.

Greenberg, M. 2014. Troubles for content II: explaining grounding. In Metasemantics: New Essays on the Foundations of Meaning, ed. A. Burgess and B. Sherman, 169-84. Oxford: Oxford University Press.

Fine, K. 2012. Guide to ground. In Metaphysical Grounding: Understanding the Structure of Reality, ed. F. Correia and B. Schnieder, 37-80. Cambridge: Cambridge University Press.

Fine, K. 2015. Unified foundations for essence and ground. Journal of the American Philosophical Association 1: 296-311.

King, P. 2005. Duns Scotus on singular essences. Medioevo 30: 111-37. 
Litland, J. 2013. On some counterexamples to the transitivity of grounding. Essays in Philosophy 14: 1932.

Rosen, G. 2010. Metaphysical dependence: grounding and reduction. In Modality: Metaphysics, Logic, and Epistemology, ed. B. Hale and A. Hoffman, 109-36. Oxford: Oxford University Press.

Rosenkrantz, G. 1993. Haecceity: An Ontological Essay. New York: Springer Academic Publications.

Schaffer, J. 2012. Grounding, transitivity, and contrastivity. In Metaphysical Grounding: Understanding the Structure of Reality, ed. F. Correia and B. Schnieder, 122-38. Cambridge: Cambridge University Press.

Skiles, A. 2014. Primitivism about intrinsicality. In Companion to Intrinsic Properties, ed. R. Francescotti, 221-52. Berlin: De Gruyter.

Sober, E. 1984. The Nature of Selection: Evolutionary Theory in Philosophical Focus. Chicago: University of Chicago Press.

Swoyer, C. 2008. Abstract entities. In Contemporary Debates in Metaphysics, ed. T. Sider, J. Hawthorne and D. Zimmerman, 12-31. Oxford: Blackwell Publishing. 